\title{
Seismic Radiation by Magma Injection: An Anomalous Seismic Event Near Tori Shima, Japan
}

\author{
HIROO KANAMORI, ${ }^{1}$ GÖRAN EKSTROM, ${ }^{2}$ ADAM DZIEWONSKI, ${ }^{2}$ \\ JEFFREY S. BARKER, ${ }^{3,4}$ AND STUART A. SIPKIN 5
}

\begin{abstract}
The earthquake with a bodywave magnitude $m_{b}=5.5$, which occurred near Tori Shima, Japan, on June 13, 1984 (origin time: 0229:25.3 UT, $31.448^{\circ} \mathrm{N}, 140.036^{\circ} \mathrm{E}$, depth of $10 \mathrm{~km}, m_{b}=5.5, M_{S}=5.5$ ) is anomalous because it generated tsunamis which are disproportionately large for the magnitude of the earthquake. At Hachijo Island, $150 \mathrm{~km}$ from the epicenter, tsunamis were visually observed with peak-to-peak amplitude of 130 to $150 \mathrm{~cm}$. Long-period seismic radiation is also anomalous. Love waves are almost absent, and Rayleigh waves are radiated with equal amplitude and phase in all directions. A simple double-couple model cannot explain these observations. With the assumption of no net volume change at the source, these data can be best explained with a compensated linear vector dipole (CLVD) with the principal tensional dipole in the vertical direction. The scalar moment of this dipole is $4 \times 10^{24}$ dyn $\mathrm{cm}$. Moment tensor inversions of long-period body waves and surface waves yield an almost identical solution. This CLVD source can be interpreted as horizontal fluid injection. The location of the event is in the Smith depression which is one of the nascent back arc basins just behind the Bonin arc. These basins are filled with thick sediments, and numerous young volcanoes are found near this site. Magmatic injection is most likely to occur in this tectonic environment. However, the time scale of the seismic event seems too short for magma injection to occur. A more likely mechanism involves water-magma interaction. The injection may be viewed as hydrofracturing driven by supercritical water heated by injected magma. The estimated volume of injected water is about $0.018 \mathrm{~km}^{3}$ and that of basaltic magma is about $10 \%$ of this. This type of deformation is more efficient for tsunami generation than faulting with the same scalar moment.
\end{abstract}

\section{INTRODUCTION}

On June 13, 1984, an earthquake with a bodywave magnitude, $m_{b}=5.5$, occurred near Tori Shima (Tori Island), Japan. (The hypocentral parameters reported by the National Earthquake Information Center are 0229:25.3 UT, $31.448^{\circ} \mathrm{N}$, $140.036^{\circ} \mathrm{E}$, depth of $10 \mathrm{~km}, m_{b}=5.5, M_{S}=5.5$, see Figure 1). This earthquake was anomalous because it generated large tsunamis which were observed at many locations in Japan [Hatori, 1985; Okada, 1984]. At Hachijo Island, $150 \mathrm{~km}$ from the epicenter (Figure 1), tsunamis were observed visually with a peak-to-peak amplitude of 130 to $150 \mathrm{~cm}$. Along the Japanese coast, 400 to $500 \mathrm{~km}$ from the epicenter, tsunamis as high as $58 \mathrm{~cm}$ (peak-to-peak amplitude) were observed on tide gauges. These tsunamis are disproportionately large for the magnitude of the earthquake. Hatori [1985] assigned this event a tsunami magnitude of $m=0$. Normally, only earthquakes with $M_{w}=7.2$ can generate tsunamis of this magnitude [Hatori, 1978]. According to Hatori [1985], the first motion of the tsunami was up at two locations. At another location, it was down but ambiguous.

\footnotetext{
${ }^{1}$ Seismological Laboratory, Califomia Institute of Technology, Pasadena.

${ }^{2}$ Department of Earth and Planetary Sciences, Harvard University, Cambridge, Massachusetts.

${ }^{3}$ Woodward-Clyde Consultants, Pasadena, Califomia.

${ }^{4}$ Now at Department of Geological Sciences and Environmental Studies, State University of New York at Binghamton.

${ }^{5}$ U.S. Geological Survey, Denver, Colorado.
}

Copyright 1993 by the American Geophysical Union.

Paper number 92JB02867.

0148-0227/93/92JB-02867\$05.00
At other locations, the first motions could not be determined. Satake and Kanamori [1991] showed that the large tsunamis observed at the Japanese coast are partially due to focussing of tsunami energy along the path.

In the Bonin arc where this earthquake occurred, underwater volcanic eruptions are frequent. Many of these resulted in the formation of new islands (e.g., 1952 Myojin Reef [Morimoto and Ossaka 1955], 1973 Nishino-jima Shinto, 1985 North Iwo Jima, see Figure 1). There is no positive evidence, however, for underwater volcanic eruptions associated with this event (A. Kubotera, personal communication, 1985).

Except for the anomalous tsunamis, no obviously unusual observations have been reported. In view of the importance of this event in relation to magmatic processes and tsunami generation, we made a detailed analysis of global seismic data observed for this earthquake. We will show that under the assumption of no net volume change, this earthquake can be best represented by a compensated linear vector dipole (CLVD) rather than the conventional double force couple.

Ishimoto [1932] argued that most earthquakes are caused by sudden magma injection and proposed this type of source. Subsequent studies, however, have demonstrated that almost all earthquakes are caused by faulting and can be adequately represented by a double couple.

Seismic sources with a CLVD mechanism have been proposed for some seismic events. The most recent example is the Mammoth Lakes earthquake in California presented by Julian [1983] and Julian and Sipkin [1985]. Sipkin [1986] made a systematic study of nondouble-couple events and concludes that source multiplicity, rupture on nonplanar fault surfaces, and tensile failure under high fluid pressure (injection) may cause a nondouble-couple solution. Sipkin argued, on the basis of the result of his time-dependent inversion technique, that injection is the most likely mechanism of the Mammoth Lakes earthquake. Ekström [1983] and Wallace [1985], however, offered an altemative 


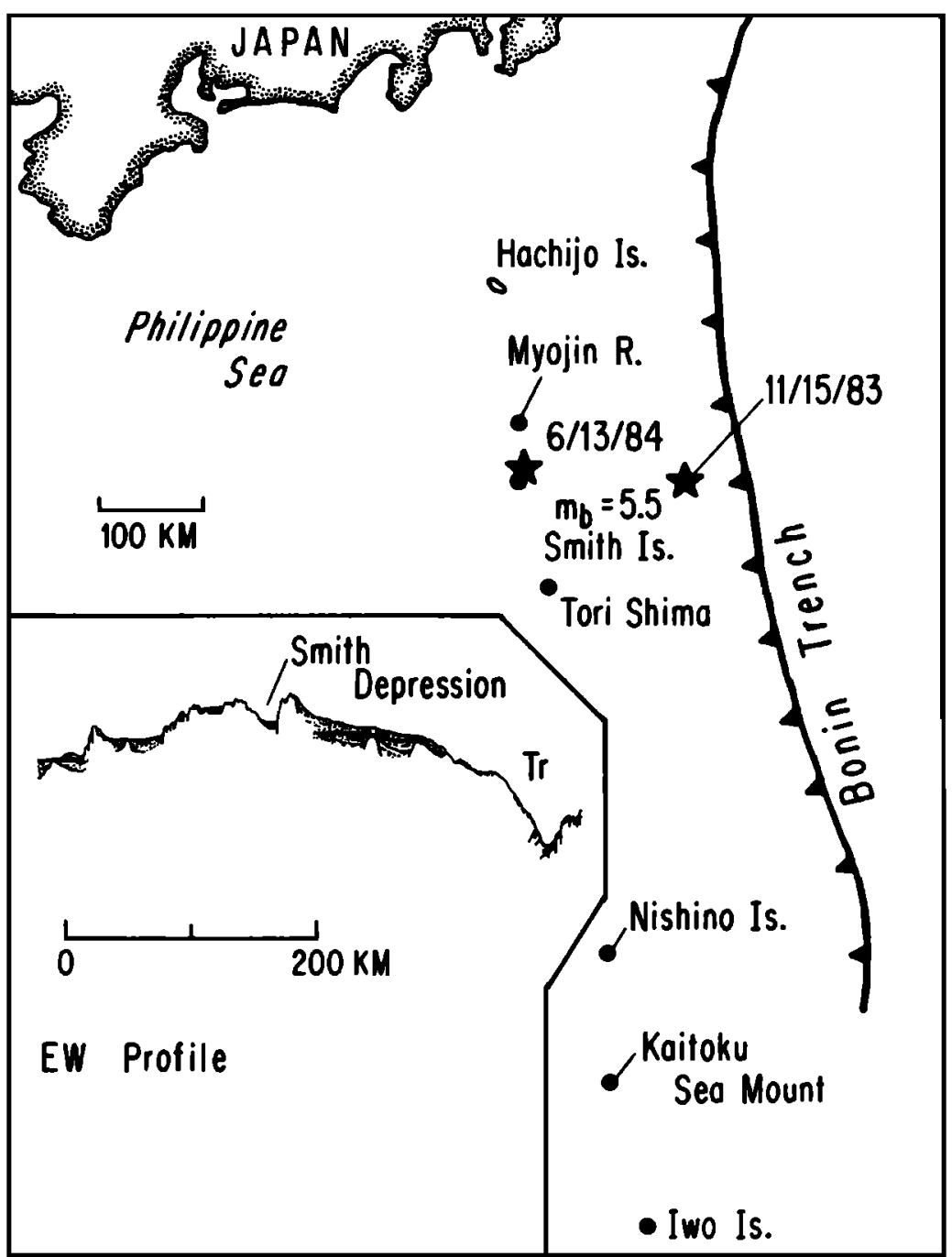

Fig. 1. Location of the 1984 Tori Shima earthquake (June 13, 1984). The inset shows the $\mathrm{E} / \mathrm{W}$ profile passing the epicenter [after Honze and Tamaki, 1985]. The epicenter of the thrust event (November 15, 1983) used for comparison is also shown.

explanation (complex source) for the mechanism of that earthquake.

\section{LONG-PERIOD SURFACE WAVES}

The most unusual feature of the 1984 Tori Shima earthquake is the absence of long-period Love waves. Figure 2a shows long-period seismograms recorded at stations of the Global Digital Seismographic Network (GDSN). We filtered the original seismograms with a low-pass filter with a cutoff period of $30 \mathrm{~s}$. In Figure 2 the vertical and the transverse components have a common amplitude scale. Although we could retrieve both vertical and transverse components from only six stations, the azimuthal coverage is satisfactory. Since surface wave radiation pattems are symmetric at the source, an azimuthal coverage over only $180^{\circ}$ is needed to determine the mechanism. At all the stations, Love waves are negligible compared with Rayleigh waves. At the station CHTO, some energy is observed on the transverse component, but the distance is only $39^{\circ}$ and the multiple $S$ phases are not clearly separated from the Love wave. Both Love and Rayleigh waves are excited equally well by any double-couple source. To demonstrate this, we show in Figure 2b seismograms from an ordinary thrust earthquake (November 15, 1983) which occurred near the Tori Shima earthquake. The difference between Figures $2 \mathrm{a}$ and $2 \mathrm{~b}$ is obvious and suggests a nondouble couple origin of the Tori Shima earthquake.

Long-period Rayleigh waves were also recorded at the stations of the International Deployment of Accelerographs (IDA) network. We inverted the Rayleigh wave spectra to determine the source mechanism using the method described by Kanamori and Given [1981]. Since the event is shallow, the moment tensor elements $M_{z x}$ and $M_{z y}$ (for notation, see Kanamori and Given [1981]) cannot be determined and are assumed to be zero. The isotropic component is also assumed to be zero. The effect of isotropic component will be discussed later. We inverted the data at periods of 160 , $176,204,232$, and $256 \mathrm{~s}$, and the results are summarized in Table 1. In Table $1, \lambda_{1}, \lambda_{2}$, and $\lambda_{3}$ are the eigenvalues of the moment tensor $\left(\left|\lambda_{1}\right| \geq\left|\lambda_{2}\right| \geq\left|\lambda_{3}\right|\right)$. Then the moment tensor can be decomposed into two parts, one representing a double couple with a scalar moment of $\left|\lambda_{1}+2 \lambda_{3}\right|$ and the other a CLVD with strength of $\left|2 \lambda_{3}\right|$. The ratio $\varepsilon=\left|2 \lambda_{3} / \lambda_{1}\right|$ gives the contribution of the CLVD source to the total moment. The source process time is approximately $10 \mathrm{~s}$ at periods of 160 , 
a. Tori Shima Earthquake 6/13/1984

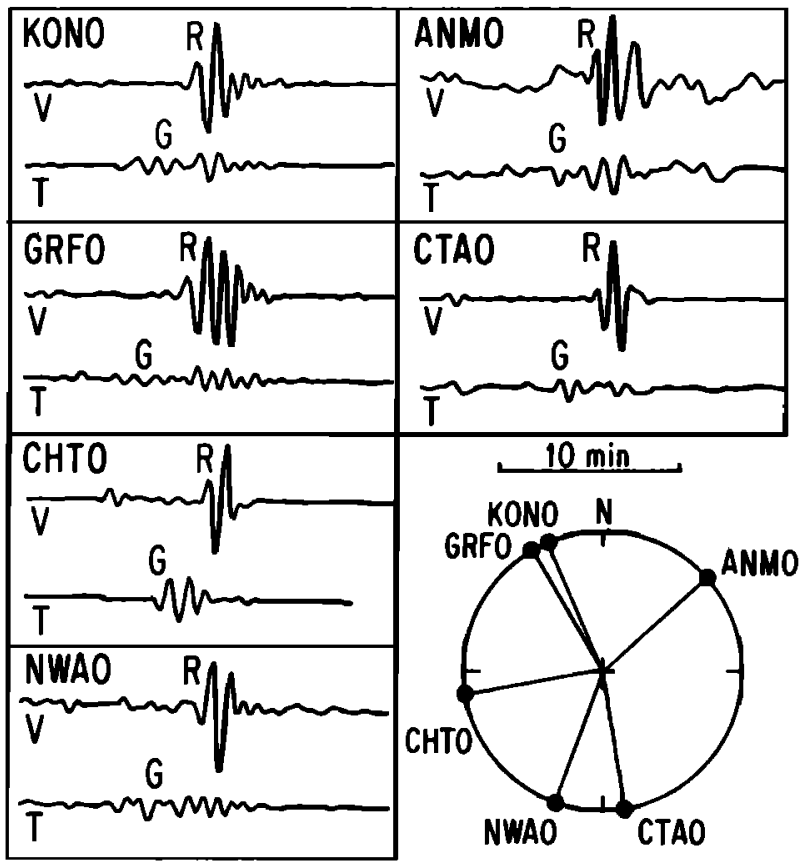

b. Thrust Earthquake

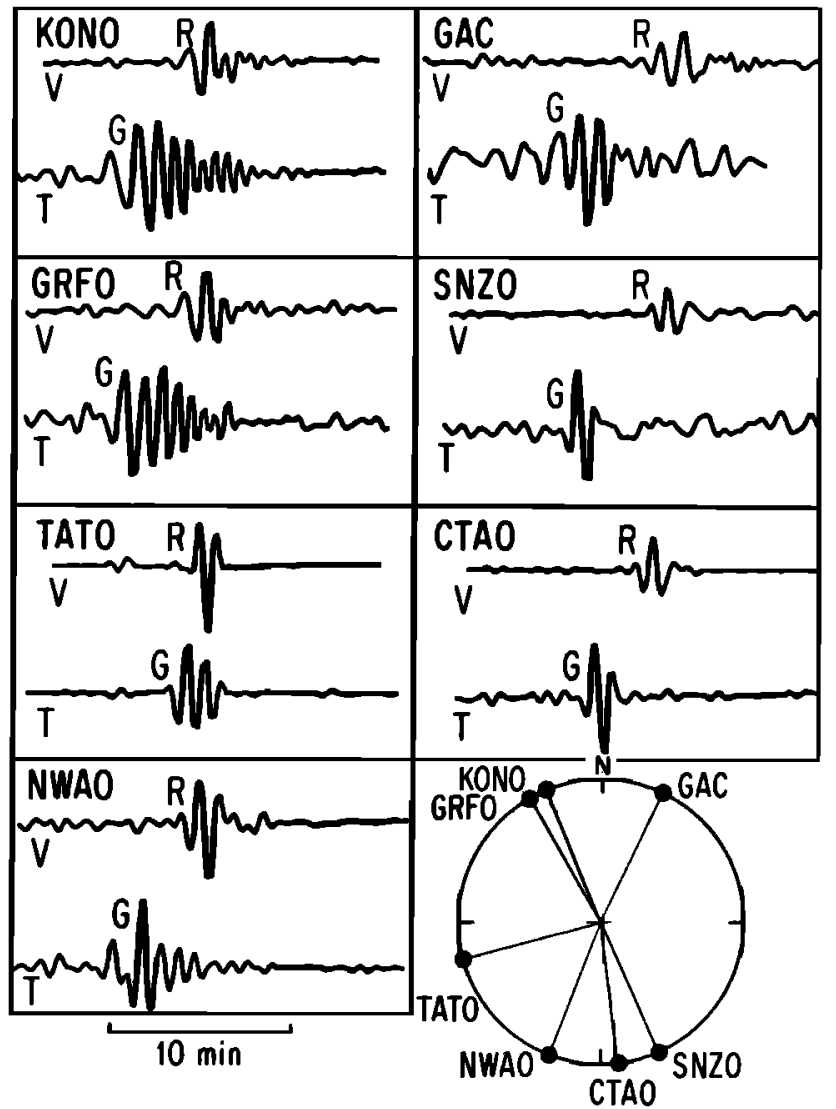

Fig. 2. (a) Vertical $(V)$ and transverse $(T)$ component of filtered GDSN long-period seismograms. Both components have a common amplitude scale. Rayleigh wave trains are marked by $R$ and the predicted arrival times of Love waves are marked by $G$. Note the absence of Love waves at all the stations. The azimuthal distribution of stations is shown on a circular diagram. (b) A similar figure for the nearby thrust earthquake which occurred on November 15, 1983. Note the difference in the Rayleigh to Love wave amplitude ratio between the two events.

176, and $204 \mathrm{~s}$. It increases to 20 and $40 \mathrm{~s}$ at 232 and 256 $s$ periods, respectively. The solutions obtained at different periods are similar, except that the total scalar moment $\left|\lambda_{1}\right|$ increases with the period. Because of the small magnitude of the event, the signal-to-noise ratio at periods much longer than $200 \mathrm{~s}$ is poor. On the other hand, the data at shorter periods are contaminated by Earth's heterogeneity. Hence we consider the result at $204 \mathrm{~s}$ to be the most reliable. The phase and amplitude data at this period are compared with the model values in Figure 3a. The amplitudes and phases of the
Rayleigh wave spectrum are about the same at all stations, and the $\varepsilon$ value is 0.87 , indicating that the source is an almost pure CLVD. The anomalously large amplitude at KIP is probably due to focussing of energy caused by lateral heterogeneities of Earth. The amplitude of odd order Rayleigh waves at KIP from events in the Japanese region is usually about 50\% larger than expected [e.g., Kanamori and Astiz, 1985].

If we force the solution to be a double couple, we obtain a fault model shown in Figure $3 \mathrm{~b}$. Since the available

TABLE 1. Mornent Tensor Solution for the Tori Shima Earthquake

\begin{tabular}{|c|c|c|c|c|c|c|c|c|}
\hline & \multirow[b]{2}{*}{160} & \multicolumn{5}{|c|}{ Long-Period Rayleigh Wave, $s$} & \multirow[b]{2}{*}{$B+M^{\dagger}$} & \multirow[b]{2}{*}{$B+M^{\dagger \dagger}$} \\
\hline & & 176 & 204 & 232 & 256 & $\mathbf{B}^{*}$ & & \\
\hline$M_{x x}$ & -0.16 & -0.17 & -0.20 & -0.21 & -0.22 & -0.22 & -0.18 & -0.087 \\
\hline$M_{y \gamma}$ & -0.16 & -0.17 & -0.20 & -0.30 & -0.42 & -0.18 & -0.19 & -0.091 \\
\hline$M_{72}$ & 0.32 & 0.34 & 0.39 & 0.51 & 0.66 & 0.40 & 0.38 & 0.61 \\
\hline$M_{x y}$ & -0.030 & -0.062 & 0.019 & 0.033 & 0.0025 & -0.064 & -0.038 & -0.039 \\
\hline$M_{2 x}$ & -- & - & -. & -- & - & 0.013 & -0.096 & -0.094 \\
\hline$M_{z y}$ & -- & -. & -- & -- & -- & 0.029 & 0.062 & 0.060 \\
\hline$\lambda_{1}$ & 0.32 & 0.34 & 0.39 & 0.51 & 0.66 & 0.40 & 0.40 & 0.63 \\
\hline$\lambda_{2}$ & -0.19 & -0.23 & -0.22 & -0.31 & -0.42 & -0.27 & -0.23 & -0.13 \\
\hline$\lambda_{3}$ & -0.13 & -0.11 & -0.17 & -0.19 & -0.24 & -0.13 & -0.17 & -0.068 \\
\hline$\left|2 \lambda_{3}\right|$ & 0.26 & 0.22 & 0.34 & 0.38 & 0.48 & 0.26 & 0.34 & -- \\
\hline$\left|\lambda_{1}+2 \lambda_{3}\right|$ & 0.060 & 0.12 & 0.050 & 0.13 & 0.18 & 0.14 & 0.06 & -- \\
\hline$\varepsilon$ & 0.81 & 0.65 & 0.87 & 0.75 & 0.73 & 0.65 & 0.85 & -- \\
\hline
\end{tabular}

Note that moment tensor is in units of $10^{25}$ dyn $\mathrm{cm}$.

*Body wave only.

$\dagger_{\text {Body wave and mantle wave. }}$

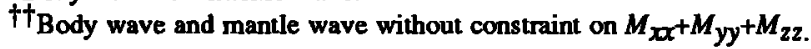




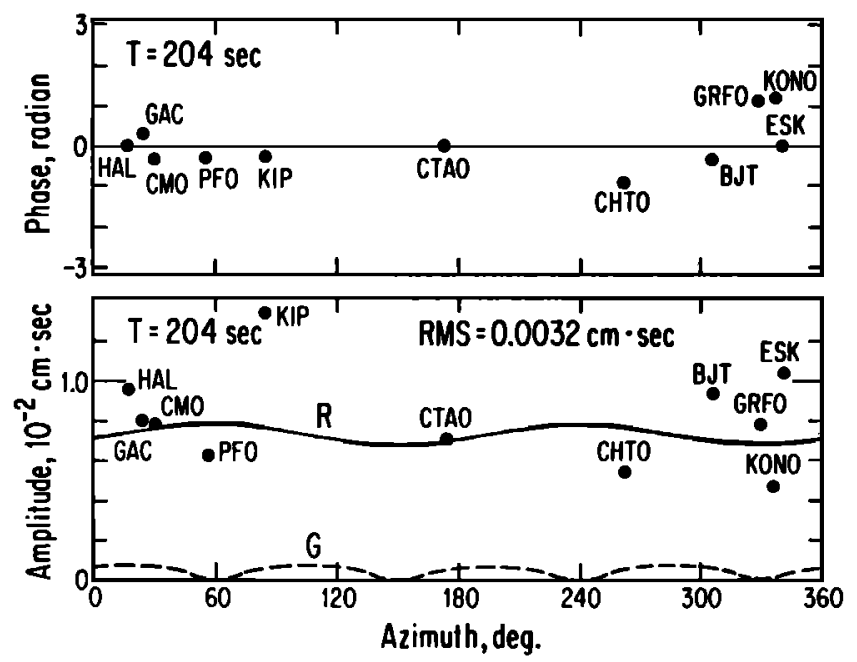

Fig. 3a. The phase and amplitude spectram of Rayleigh waves as a function of azimuth at a period of $204 \mathrm{~s}$. The solid curve shows the theoretical values for the source determined by inversion. The dashed curve indicates the theoretical amplitude spectrum of Love waves.

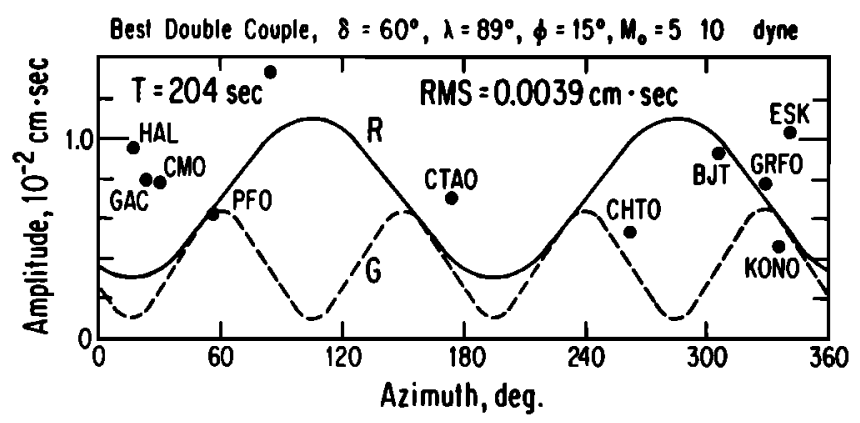

Fig. 3b. The Rayleigh wave amplitude spectrum. The data (solid circles) are the same as in Figure 3a. The solid curve is the amplitude spectrum for the best double-couple solution. The dashed curve is the Love wave amplitude spectrum computed for the best double-couple solution .

Rayleigh wave records are relatively few, the Rayleigh wave data alone cannot reject double couple models, as shown in Figure 3b. However, the root-mean-square of the misfit of the spectrum for this case is $0.0039 \mathrm{~cm} \mathrm{~s}$, which is larger than that for the CLVD solution, $0.0032 \mathrm{~cm} \mathrm{~s}$. The most obvious diagnostic for the CLVD source is the amplitude of Love waves. As shown in Figure 3a, the predicted amplitude of Love waves for the CLVD solution is close to zero at all stations, which is consistent with the observation. In contrast, the maximum Love wave amplitude for the best double-couple is $58 \%$ of that of Rayleigh waves (Figure $3 \mathrm{~b}$ ), which is inconsistent with the data. Thus the CLVD source is much more preferable than the best double couple model.

\section{Centroid Moment Tensor}

The centroid moment tensor (CMT) solution for this event published by Dziewonski et al. [1985] has a large nondouble-couple component as shown in Table 1 and Figure 4. As shown in Table 1, this solution is similar to that obtained from long-period surface waves described above, but it is intermediate between double couple and CLVD mechanism. Because of the small magnitude of this event, their solution is based on only body wave data.

In order to compare the CMT solution with that we obtained from long-period surface waves, we included mantle waves (Love and Rayleigh waves recorded at the GDSN stations) in the inversion for the CMT solution. We tried two inversions. In the first inversion the isotropic component is assumed to be zero. The result is shown in Table 1. Compared with the solution obtained from body wave data alone, this solution is closer to CLVD and is thore similar to the solution obtained from long-period surface waves at the period of $204 \mathrm{~s}$. If the solution is forced to be a double couple, no stable solution was obtained. The good agreement between the results obtained using different data sets and methods suggests that this event is indeed represented by a CLVD type source, at least at long periods.

In the second inversion, the constraint $M_{x x}+M_{y y}+M_{z z}=0$ is removed. In general, a trade-off exists between $M_{z z}$ and $M_{x x}+M_{y y}$, and the isotropic component cannot be determined well in this type of inversion. The variance reduction is from 0.51617 to 0.51463 , which is considered insignificant. As shown in Table 1, the solution indicates essentially a vertical dipole which can be decomposed into an explosive isotropic source and a CLVD.

\section{BoDY WAVE}

The $P$ waveforms recorded by GDSN long-period seismographs are shown in Figure 4. All the stations for which the first motions could be read indicate upward motions. However, at GUMO, TATO, and MAJO the first upward motion is very small and is followed by a large downward motion. The first-motion data are consistent with the moment tensor solutions shown in Table 1.

The $S H$ waves are generally very small compared with $S V$ waves at all stations. This observation together with the upward $P$ motions at all the stations is consistent with the CLVD mechanism obtained from long-period surface waves. Figure 5 compares the body waves from the Tori Shima earthquake with those from an ordinary thrust earthquake. For the ordinary earthquake, the $S H$ waves are, when averaged over the azimuth, generally significantly larger than $P$ waves. This difference again demonstrates the unusual character of the Tori Shima earthquake.

We performed moment tensor inversions of $P$ and $S H$ waves to investigate the details of the source. Because of the unusual nature of this event we used several different methods. In all body wave inversions, however, the isotropic component is assumed to be zero.

One method, developed by Sipkin [1982], treats each element of the moment tensor as a separate function of time, thus allowing us to test the hypothesis that the event was a multiple rupture with different orientations for the subevents. The results of this inversion (Figure 6a and Table 2) indicate that this event had a simple time history, with a duration of $12 \mathrm{~s}$, and no change in orientation. Most of the moment release is concentrated toward the end of the source pulse. The minimum in the mean-squared-error versus depth usually occurs at, or very near, a minimum in the $\varepsilon$ versus depth curve [Sipkin, 1986]. For moderate sized earthquakes, $\varepsilon$ is usually very small; for over $80 \%$ of the earthquakes studied using this method $\varepsilon$ is less than 0.2 . For the Tori Shima event, however, the minimum in $\varepsilon$ at the depth where the mean-squared-error was at a minimum had a value of 0.73 , indicating that there is no double-couple mechanism that can satisfactorily fit the long-period body wave data. 

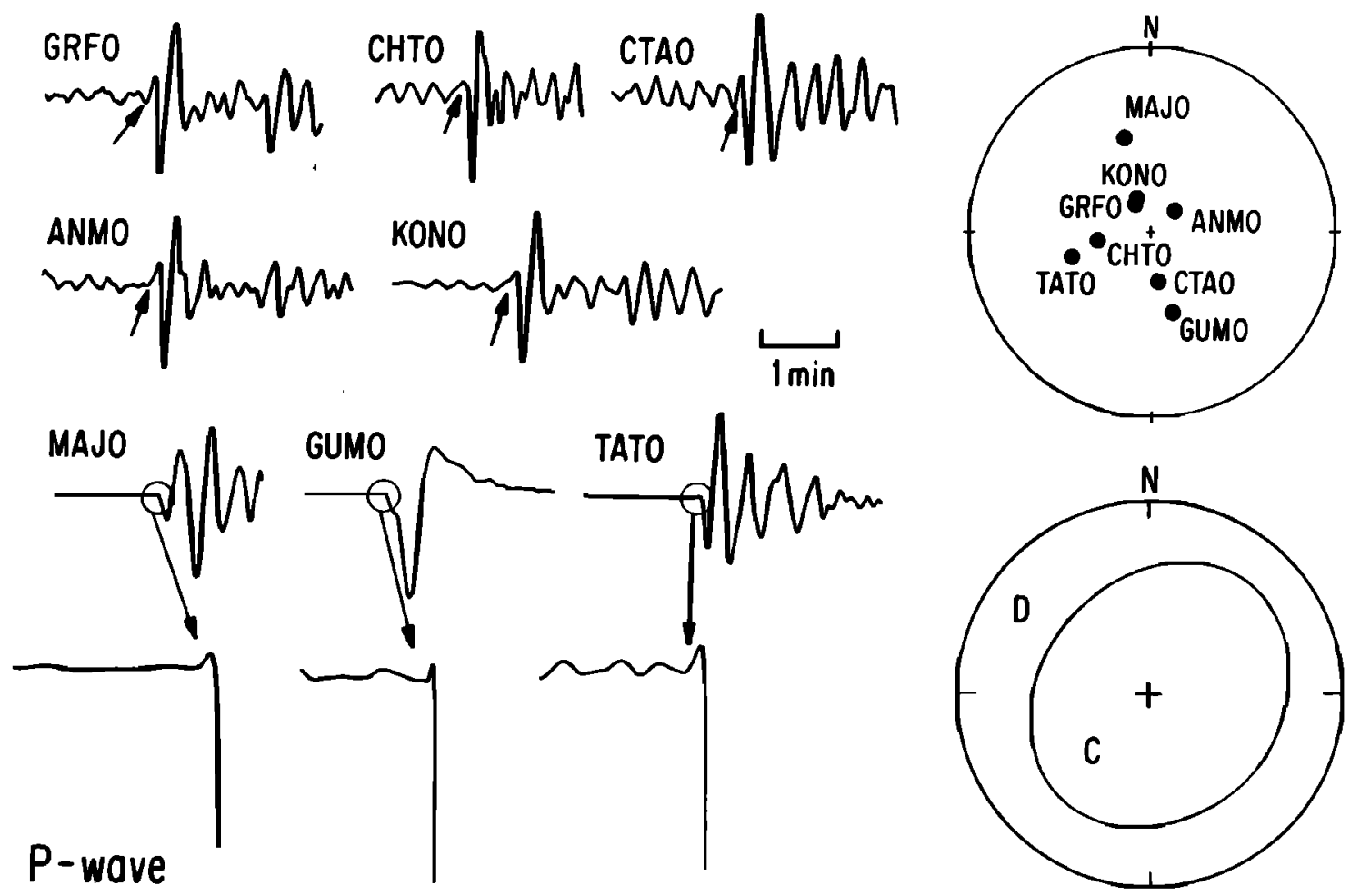

Fig. 4. $P$ waveforms and the first-motion data. The mechanism diagram of the CMT solution obtained by Dziewonski et al. [1985] is shown.

An inversion was also attempted using a more realistic oceanic structure, SOD-1, determined by Spudich et al. [1978]. The results of this inversion yielded a very similar solution with a somewhat higher value of $\varepsilon$ but with a larger misfit to the data.

A second method, developed by Ekström [1989], inverts broadband (1 $\mathrm{Hz}$ to $100 \mathrm{~s}) P$ waveforms simultaneously with the CMT data set for the moment tensor elements, the focal depth, and the source time function. Seven broadband records were constructed from digital short- and long-period seismograms, and the inversion results again showed that the data were best explained with a moment tensor which is closer to a CLVD than to a double-couple (Figure $6 \mathrm{~b}$ and Table 3). In order to be well fit, the broadband waveforms required an unusually large (10 s) source duration as well as a very shallow focus, probably in the top few kilometers of sediments on the ocean floor.

A close examination, however, revealed that if the event occurred within a few kilometers beneath the ocean bottom, an ordinary double-couple mechanism could also produce very small $S H / P$ ratio. This situation is discussed by Barker and Kanamori [1986] and can be explained as follows. For a dip-slip mechanism, the direct phase and the surface reflections are of opposite polarity. Hence if the source is very shallow, the direct wave and the surface reflections cancel out, producing small $P$ and $S H$ waves. If the event occurred in the sediments beneath the ocean bottom, most $\boldsymbol{P}$ wave energy radiated upward will go into the water layer and the main energy reflection occurs at the water surface. Because of this extra path in the water, the surface reflection, being delayed, does not cancel the direct wave. In contrast, the $S H$ wave is always reflected at the ocean bottom, and the direct and reflected phases cancel each other almost completely, resulting in a small $S H / P$ ratio. Since this behavior depends very critically on the structure and the depth, we performed a more detailed inversion of body waves using a crustal structure appropriate for the epicentral region of the Tori Shima earthquake.

The velocity structure we used is taken from Den [1972] and is shown in Table 4. This structure has been determined from a refraction profile in the vicinity of the epicenter, and has a $1.5-\mathrm{km}$-thick water layer underlain by low-velocity sedimentary layers. The source depth is taken as $4.5 \mathrm{~km}$ (i.e., $3 \mathrm{~km}$ beneath the ocean floor) on the basis of modelling of stacked short-period waveforms using the same structure model. The inversion was performed using the method of Barker and Langston [1982] on 48 teleseismic $P$ and $S H$ waveforms. The inversion results are shown in Figure 7. The solution is again a nearly pure CLVD with the primary dipole (tension) plunging $80^{\circ} \mathrm{SE}$. The duration of the time function is $6 \mathrm{~s}$, which is shorter than that estimated from long-period surface waves. This difference indicates that the overall process time of the source is somewhat longer than that indicated by the time function shown in Figure 7.

The above results confirmed the CLVD source for the Tori Shima earthquake with the assumption of vanishing isotropic component.

\section{ISOTROPIC COMPOENT}

In the analysis presented above, we imposed the constraint $M_{x x}+M_{y y}+M_{z z}=0$ in all cases except in the second CMT inversion. The above constraint is usually imposed in seismic source inversions for shallow events because of the trade-off between $M_{z z}$ and $M_{x x}+M_{y y}$. 


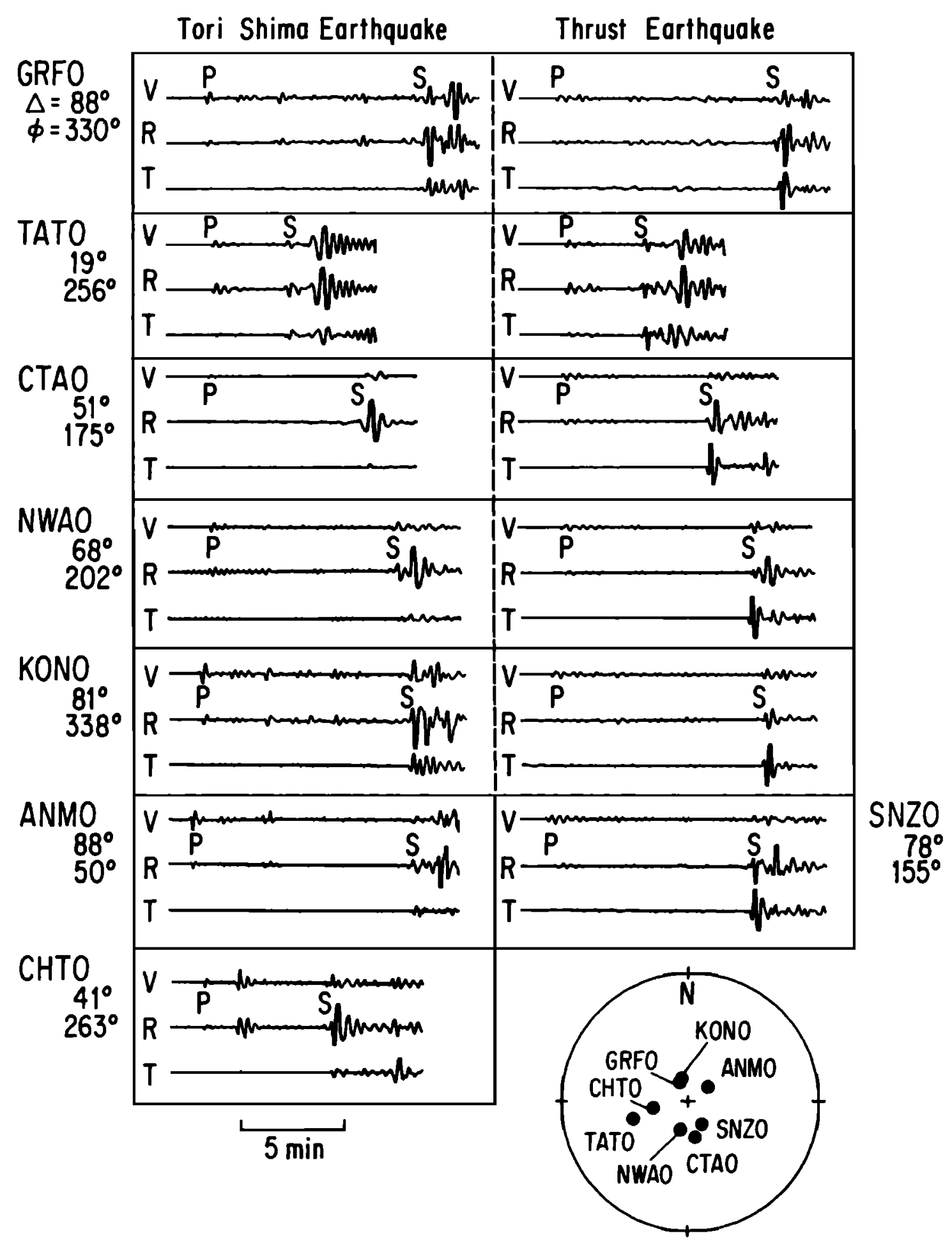

Fig. 5. Three-component (vertical, radial, and transverse) records of $P$ and $S$ waves for the Tori Shima earthquake and the thrust earthquake on November 15, 1983. Note the difference in the $P$ to $S H$ amplitude ratio between the two earthquakes.

Although this trade-off is not so obvious in general, we can examine it in some detail for our case where $M_{x y} \approx M_{x z} \approx M_{y z} \approx 0$ and $M_{x x} \approx M_{y y}$. Using the expression (equation 2) of Kanamori and Given [1981], the source spectrum of the vertical component of Rayleigh waves is given as a function of angular frequency $\omega$ by

$$
\hat{V}(\omega)=\left(S_{R}^{(1)}+N_{R}^{(1)}\right) M_{z z} / 3+\left(2 N_{R}^{(1)}-S_{R}^{(1)}\right)\left(M_{x z}+M_{y y}\right) / 6
$$

where $S_{R}^{(1)}$ and $N_{R}^{(1)}$ are the excitation functions. If we write $M_{x x}+M_{y y}=k M_{z z}$, then

$$
\hat{V}(\omega)=\left[(2-k) S_{R}^{(1)} / 6+(1+k) N_{R}^{(1)} / 3\right] M_{z z}
$$

When $k=-1, k=0, k=2 / 3$ and $k=2$, this represents CLVD, vertical dipole, net horizontal injection (with volume change 
P

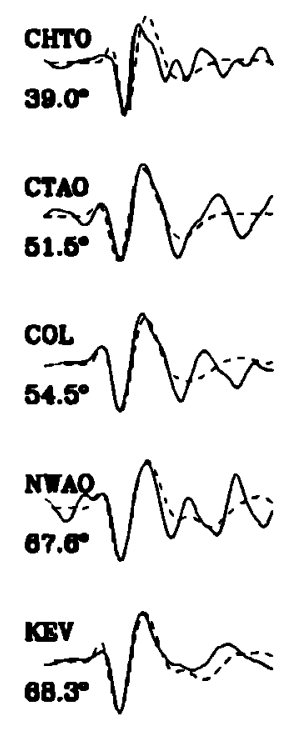

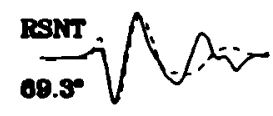
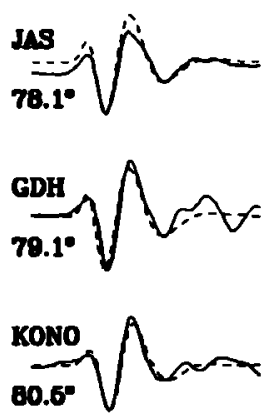
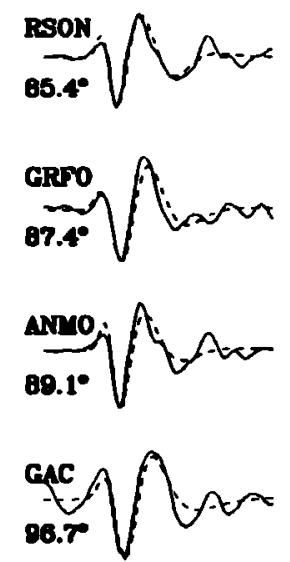

$\mathrm{SH}$

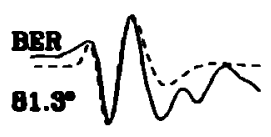

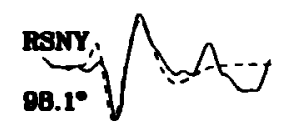
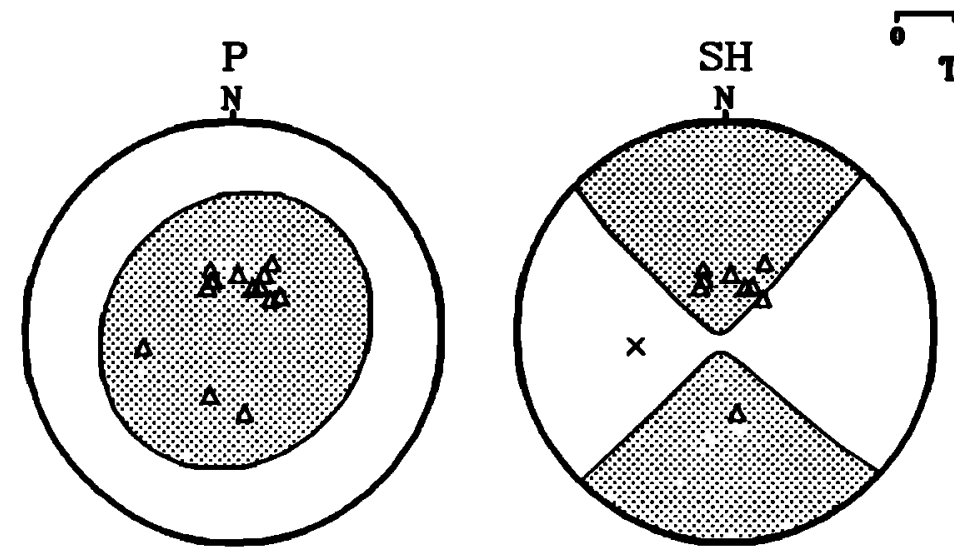

Time (s)
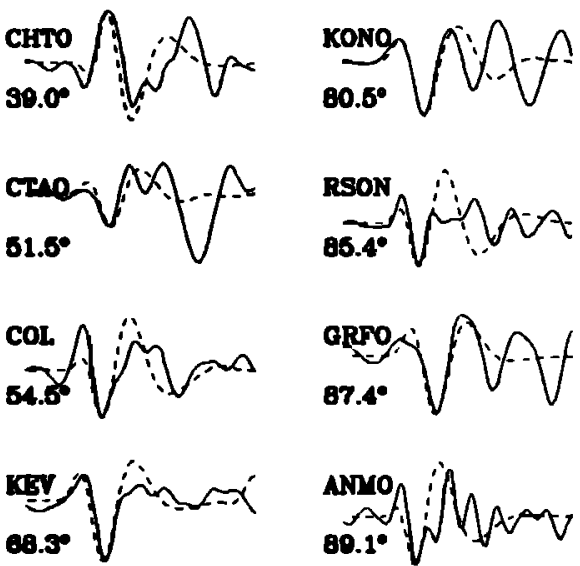

Fig. 6a. Inversion of long-period $P$ and $S H$ waves using Sipkin's [1982] method. The observed records (solid) and synthetic records (dotted) are compared. The radiation pattems of $\boldsymbol{P}$ and $S H$ waves for the moment tensor solution and the source time function are shown at the bottom.

TABLE 2. Body Wave Moment Tensor Solution

\begin{tabular}{|c|c|c|c|}
\hline Principal Axes & $\lambda$ & Plunge & Azimuth \\
\hline$T$ & 3.92 & $89^{\circ}$ & $64^{\circ}$ \\
\hline I & -1.43 & $1^{\circ}$ & $223^{\circ}$ \\
\hline $\mathbf{P}$ & -2.50 & $0^{\circ}$ & $313^{\circ}$ \\
\hline
\end{tabular}

Number of stations is: $15 P$ phases and $10 S H$ phases. Depth is 7 $\mathrm{km}$. Moment tensor (unit of $10^{24} \mathrm{dyn} \mathrm{cm}$ ): $M_{r r}=M_{z z}=3.92, M_{\theta \theta}$ $=M_{x x}=-1.92, M_{\phi \phi}=M_{y y}=-2.00, M_{r \theta}=M_{x z}=0.03, M_{r \phi}=-M_{y z}=-$
$0.08, M_{\theta \phi}=-M_{x y}=-0.53$ Nondouble-couple omponent $\Theta=0.73$.

and $\lambda=\mu$ ), and isotropic explosion, respectively. The moment tensors and the source spectra are given by

$$
\begin{aligned}
& \left(\begin{array}{ccc}
-M_{z z} / 2 & 0 & 0 \\
0 & -M_{z z} / 2 & 0 \\
0 & 0 & M_{z z}
\end{array}\right), \hat{V}(\omega)=S_{R}^{(1)} M_{z z} / 2 \quad \text { (CLVD), } \\
& \left(\begin{array}{ccc}
0 & 0 & 0 \\
0 & 0 & 0 \\
0 & 0 & M_{z z}
\end{array}\right), \hat{V}(\omega)=\left(S_{R}^{(1)}+N_{R}^{(1)}\right) M_{z z} / 3 \quad \text { (vertical dipole), }
\end{aligned}
$$

$$
\left(\begin{array}{ccc}
M_{z z} / 3 & 0 & 0 \\
0 & M_{z z} / 3 & 0 \\
0 & 0 & M_{z z}
\end{array}\right), \quad \begin{array}{r}
\hat{V}(\omega)=2\left[S_{R}^{(1)}+(5 / 2) N_{R}^{(1)}\right] M_{z z} / 9 \\
\end{array}
$$

and

$$
\left(\begin{array}{ccc}
M_{z z} & 0 & 0 \\
0 & M_{z z} & 0 \\
0 & 0 & M_{z z}
\end{array}\right) \quad \hat{V}(\omega)=N_{R}^{(1)} M_{22}
$$

(isotropic explosion),

respectively.

Thus the observed spectrum $\hat{V}(\omega)$ can be interpreted in terms of either one of these models, or any combination of them, depending on the value of $k$. Unless some independent estimate of the net volume change is available, this indeterminacy cannot be removed. A similar indeterminacy occurs in body wave analysis, and inversion without the constraint of vanishing isotropic component is unstable. This indeterminacy needs to be borne in mind in the following interpretation. 


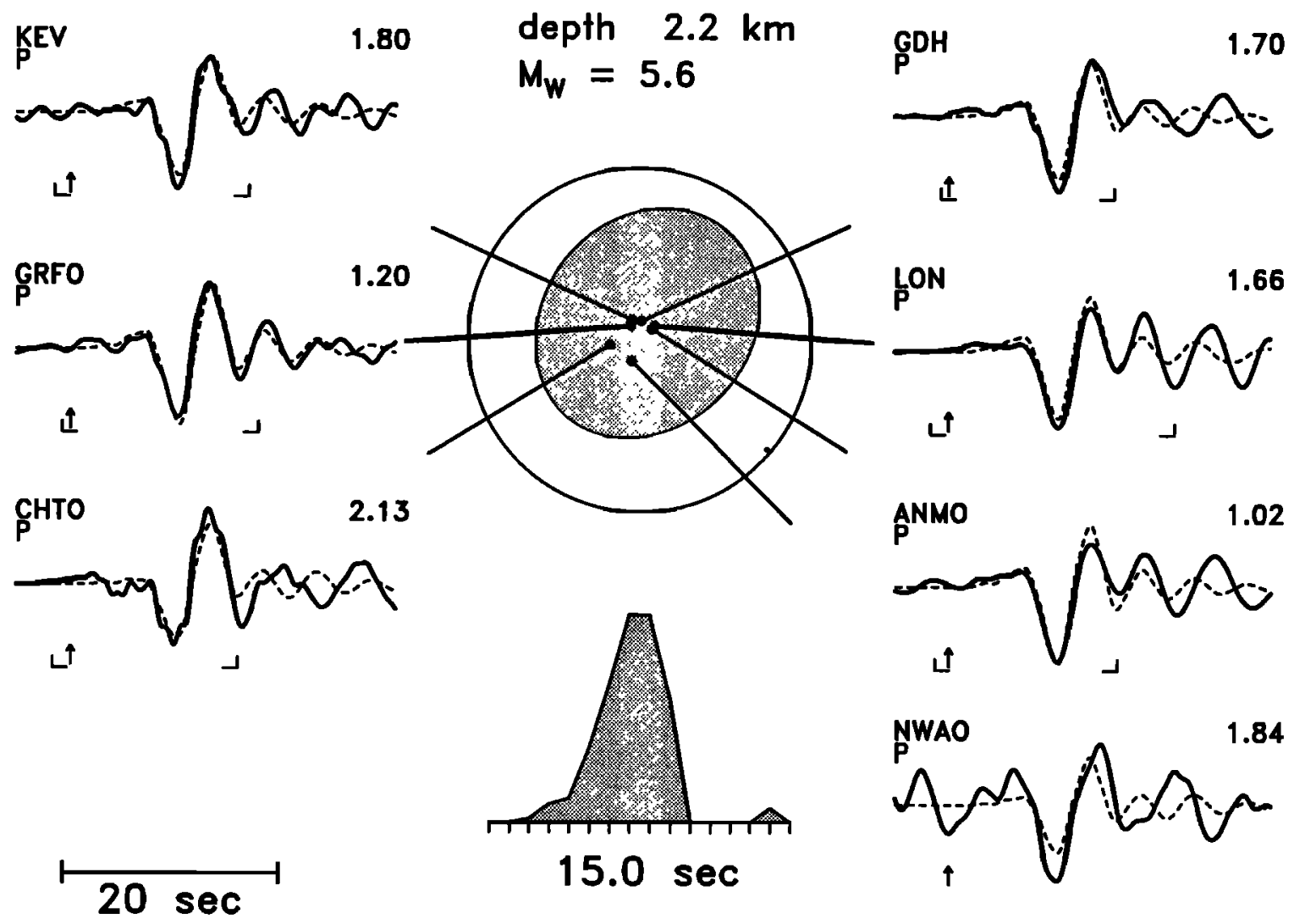

Fig. 6b. Inversion result using Ekström's [1989] method. The waveforms are displacement seismograms obtained from simultaneous deconvolution of short- and long-period channels. The observed seismograms are shown in solid, and the synthetics are shown in dashed lines. The small arrow indicates the $P$ wave arrival, and the brackets show the inversion window. The maximum amplitude is shown in microns. The NWAO trace was not used in the inversion because of the high noise level.

Table 3. Centroid Moment Tensor P Wave Solution

\begin{tabular}{cccc}
\hline Principal axes: & $\lambda$ & Plunge & Azimuth \\
\hline T & 4.35 & $80^{\circ}$ & $24^{\circ}$ \\
I & -1.35 & $9^{\circ}$ & $221^{\circ}$ \\
P & -3.00 & $2^{\circ}$ & $131^{\circ}$ \\
\hline
\end{tabular}

Depth is $2.2 \mathrm{~km}$ in the structure shown in Table 4. Moment Tensor (unit of $10^{24}$ dyn cm): $M_{r r}=M_{z z}=4.18, M_{\theta \theta}=M_{x x}=-1.91, M_{\phi \phi}=M_{y y}$ $=-2.27, M_{r \theta}=M_{x z}=0.93, M_{r \phi}=-M_{y z}=-0.32, M_{\theta \phi}=-M_{x y}=-0.87$.

Nondouble-couple component $\varepsilon=0.62$.

TABLE 4. Velocity Structure Model at the Source of the Tori Shima Earthquake

\begin{tabular}{cccc}
$\begin{array}{r}V P, \\
\mathrm{~km} / \mathrm{s}\end{array}$ & $\begin{array}{c}V_{S}, \\
\mathrm{~km} / \mathrm{s}\end{array}$ & $\begin{array}{c}\text { Density, } \\
\mathbf{g} / \mathrm{cm}^{3}\end{array}$ & $\begin{array}{c}\text { Thickness, } \\
\mathbf{k m}\end{array}$ \\
\hline 1.50 & 0.00 & 1.03 & 1.50 \\
1.80 & 1.04 & 1.30 & 0.30 \\
2.00 & 1.15 & 1.80 & 0.40 \\
3.20 & 1.85 & 2.10 & 0.50 \\
4.75 & 2.75 & 2.30 & 3.30 \\
6.52 & 3.75 & 2.50 & 4.00 \\
7.00 & 4.00 & 2.80 & 6.00 \\
8.00 & 4.60 & 3.10 & half-space \\
\hline
\end{tabular}

\section{INTERPRETATION}

The source of the Tori Shima earthquake must (1) produce long-period seismic radiation similar to that of a CLVD and (2) uplift the ocean floor enough to generate the tsunamis. With this in mind we interpret the CLVD source in terms of sudden injection of fluid in sediments. The Tori Shima earthquake is located near the Smith depression which is one of the nascent back arc basins just behind the Bonin ridge (Figure 1) [Honza and Tamaki, 1985]. These basins are filled with thick sediments, and numerous young volcanoes are found near this site. In this tectonic environment, as the pressure in a shallow magma body increases, rapid injection may occur into the overlying and surrounding soft sediments.

In our solution $M_{x x}, M_{y y}$, and $M_{z z}$ dominate. Since $M_{z z}>0$, and $M_{x x} \approx M_{y y}<0$, our solution corresponds to horizontal injection (Figure 8). We consider an injection source of volume $\Delta V$ in a horizontal layer. In this case, $M_{x x}=\lambda \Delta V, M_{y y}=\lambda \Delta V$ and $M_{z z}=(\lambda+2 \mu) \Delta V$. Here $\mu$ is the rigidity, and $\lambda$ is the Lame's constant. This can be decomposed into a CLVD source with $M_{x x}=-2 \mu \Delta V B, M_{y y}=-$ $2 \mu \Delta V / 3$ and $M_{z z}=4 \mu \Delta V / 3$, and an isotropic source with $M_{x x}=M_{y y}=M_{z z}=[\lambda+(2 / 3) \mu] \Delta V$. If the magma comes from some deeper reservoir, the isotropic component can be cancelled by removal of magma from the reservoir, and only the CLVD part contributes to seismic radiation. To estimate the total volume of injection, we take the solution obtained from the $204 \mathrm{~s}$ spectra (Table 1), and use $M_{z z}=4 \times 10^{24} \mathrm{dyn}$ $\mathrm{cm}$, and $M_{x x}=M_{y y}=-2 \times 10^{24}$ dyn $\mathrm{cm}$. All other components are negligible. Then the volume change $\Delta V$ is given by

$$
\Delta V=3 M_{z z} / 4 \mu \text {. }
$$

The estimate of $\Delta V$ then depends on the choice of $\mu$. Since injection is most likely to occur within the soft 
Tori Shima Inversion Results ( $P$ Waves)

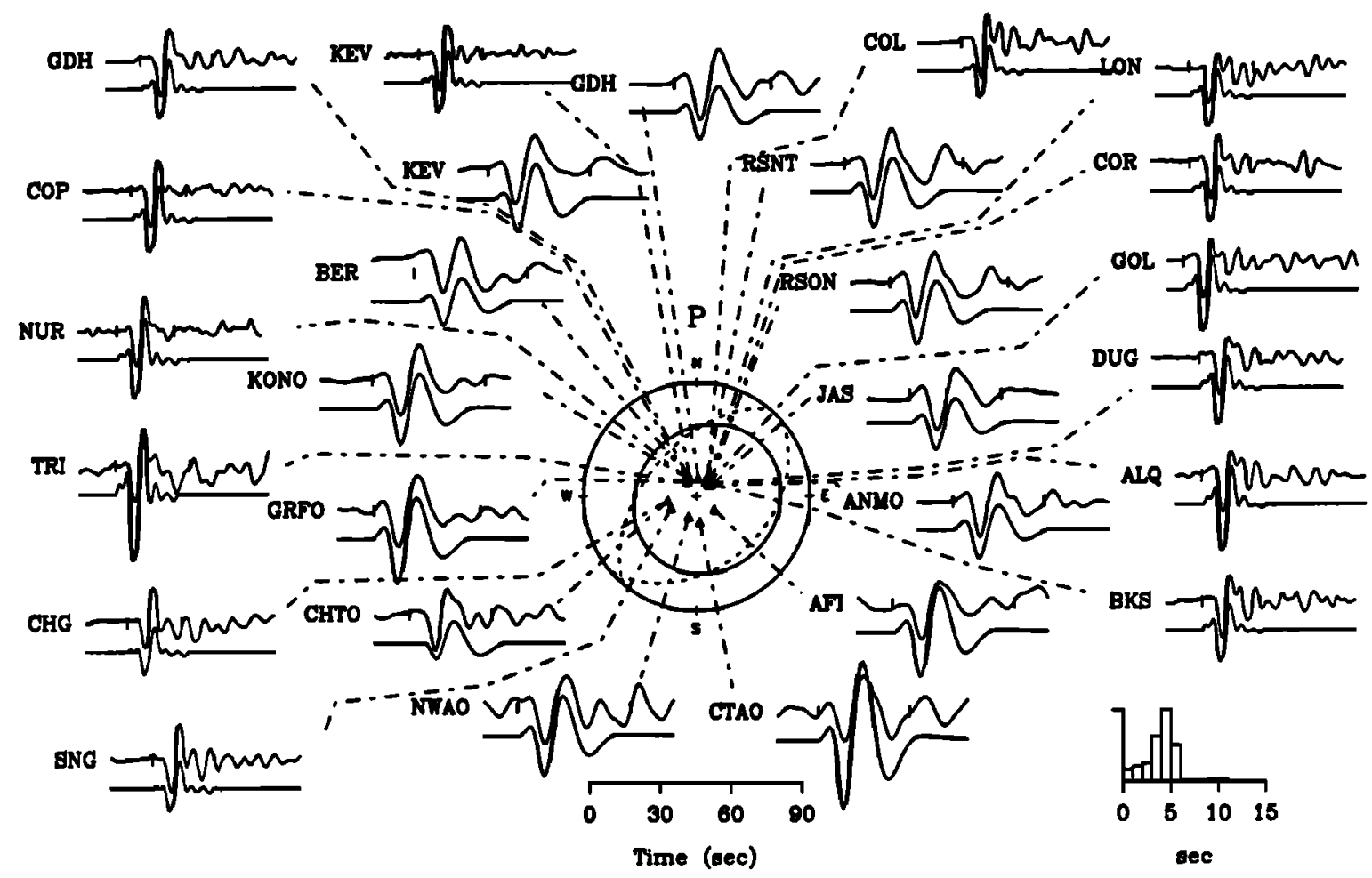

Tori Shima Inversion Results (SH waves)

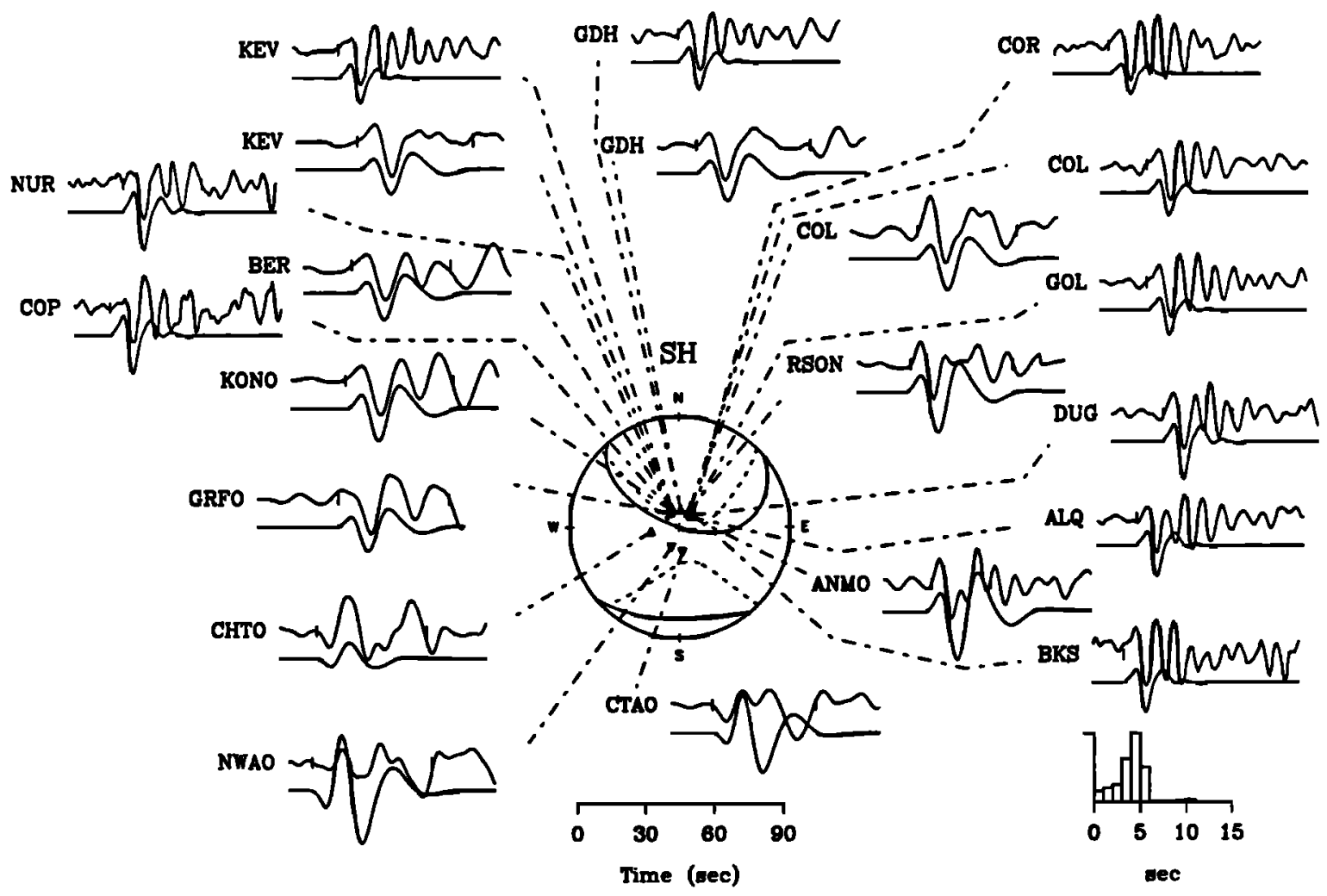

Fig. 7. Inversion of long-period $P$ and $S H$ waves using Barker and Langston's [1982] method. Synthetic waveforms are shown below the observed waveforms. The solid and dashed curves in the mechanism diagrams indicate the moment tensor and the best double-couple solutions, respectively. 


\section{Magma Injection Magma $+\mathrm{H}_{2} \mathrm{O}$ Injection}
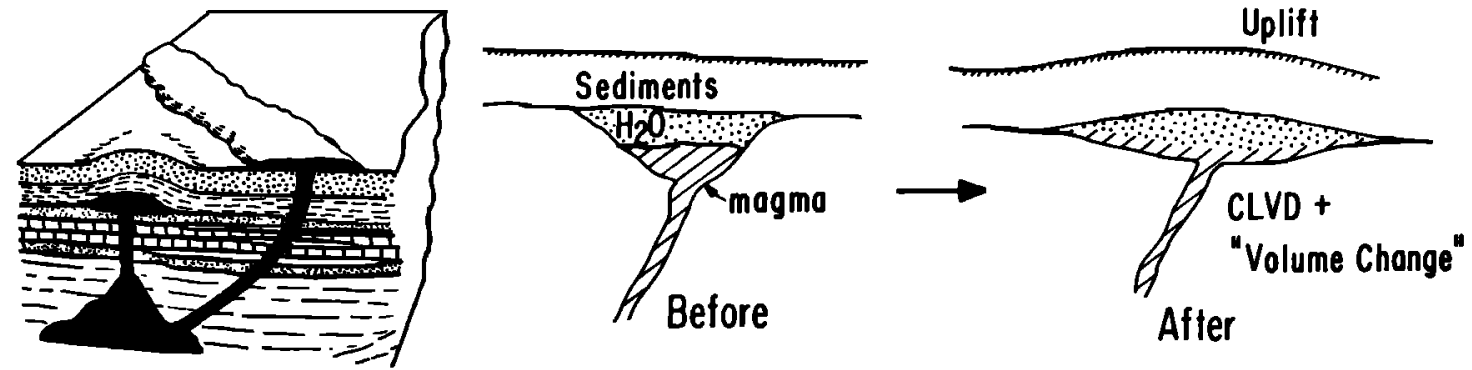

Fig. 8. Schematic diagram of magma injection in sediments (left). The two figures on the right show injection of magma into water-filled sediments and subsequent explosion when the magma-water mixture is heated.

sediments, a representative value of rigidity near the source is probably relatively small, of the order of $5 \times 10^{10}$ dyn $/ \mathrm{cm}^{2}$. However, the structures we used for modelling seismic waves have a rigidity of $0.7 \times 10^{11}$ to $2.7 \times 10^{11}$ dyn $/ \mathrm{cm}^{2}$ at the source depth. As Heaton and Heaton [1989] pointed out, to estimate the displacement from the moment, it is more appropriate to use the rigidity of the model used for determination of the moment tensor. Hence we use an average value, $\mu=1.7 \times 10^{11} \mathrm{dyn} / \mathrm{cm}^{2}$ and obtain $\Delta V=1.8 \times 10^{13} \mathrm{~cm}^{3}\left(0.018 \mathrm{~km}^{3}\right)$. Satake and Kanamori [1991] estimated the volume of the displaced water to be $4 \times 10^{13}$ $\mathrm{cm}^{3}$ from tsunami data. The factor of 2 difference is not unreasonable in view of the uncertainties in the depth of the source and the structure of sediments near the source. Abe [1973] estimated the volume of displaced water at the source of several large earthquakes. For the 1964 Niigata earthquake $\left(M_{w}=7.4\right)$, for example, his estimate is $5 \mathrm{~km}^{3}$. Considering the smaller tsunami magnitude of the Tori Shima event, the difference in the source geometry, and the difference in the path effect demonstrated by Satake and Kanamori [1991], the volume change estimated above seems reasonable. Although no direct estimate of the source dimension is available, Satake and Kanamori [1991] suggest a dimension of 10 to $20 \mathrm{~km}$.

The time scale of the seismic event, 10 to $40 \mathrm{~s}$, may seem too short for injection to occur over a distance of $10 \mathrm{~km}$. Shaw's [1980] calculations on laminar magma injection in dikes suggest that basaltic magma (viscosity $=100 \mathrm{p}$ ) can travel $10 \mathrm{~km}$ in $10 \mathrm{~s}$ in a $1-\mathrm{m}$-wide conduit under a pressure difference of 1000 bars over $10 \mathrm{~km}$. However, at such a ' high speed, the flow becomes turbulent, and the laminar flow model is not valid (the Reynolds number is about 1000 times larger than the critical value for laminar flow), and the flow speed will be decreased considerably.

Spence and Turcotte [1985] derived self-similar solutions for two-dimensional propagation of a liquid-filled crack. They obtain, with a reasonable choice of physical parameters for basaltic magma, an injection speed of about $0.5 \mathrm{~m} / \mathrm{s}$ which is about 100 times too small to excite seismic events.

These results seem to indicate that the time constant of 10 to $40 \mathrm{~s}$ is too short for magma injection to occur. A more likely process of injection involves magma-water interaction and may occur as illustrated in Figure 8 . When a large amount of magma is injected in water-filled sediments, the volume of water increases because of heating. We assume that this process occurs in a closed system. At a pressure of 300 bars, the specific volume of water increases approximately 30 times as the temperature increases from 0 to $1000^{\circ} \mathrm{C}$ (Figure 9). Since this pressure-temperature point is above the critical point of water, the water is a supercritical fluid. Since heating of a large volume of water cannot occur very fast, this expansion takes place gradually, building up the pressure in the sediment. Eventually the pressure exceeds the strength of the sediment, and sudden injection of supercritical water (and magma) can occur in the sediments, in a manner similar to hydrofracturing. This process can be rapid enough to cause seismic radiation. In this case, however, a net volume change is likely to occur, and a source different from a pure CLVD may be more appropriate. For example, the second CMT inversion (Table 1) suggests a vertical dipole, which can be decomposed into an isotropic expansion source and a CLVD as follows:

$$
\begin{aligned}
& \left(\begin{array}{ccc}
0 & 0 & 0 \\
0 & 0 & 0 \\
0 & 0 & M_{z z}
\end{array}\right)= \\
& \left(\begin{array}{ccc}
M_{z z} / 3 & 0 & 0 \\
0 & M_{z z} / 3 & 0 \\
0 & 0 & M_{z z} / 3
\end{array}\right)+\left(\begin{array}{ccc}
-M_{z z} / 3 & 0 & 0 \\
0 & -M_{z z} / 3 & 0 \\
0 & 0 & 2 M_{z z} / 3
\end{array}\right)
\end{aligned}
$$

Using the value for $M_{z z}$ listed in Table 1 , we obtain $\Delta V=1.8 \times 10^{13} \mathrm{~cm}^{3}$, the same as above.

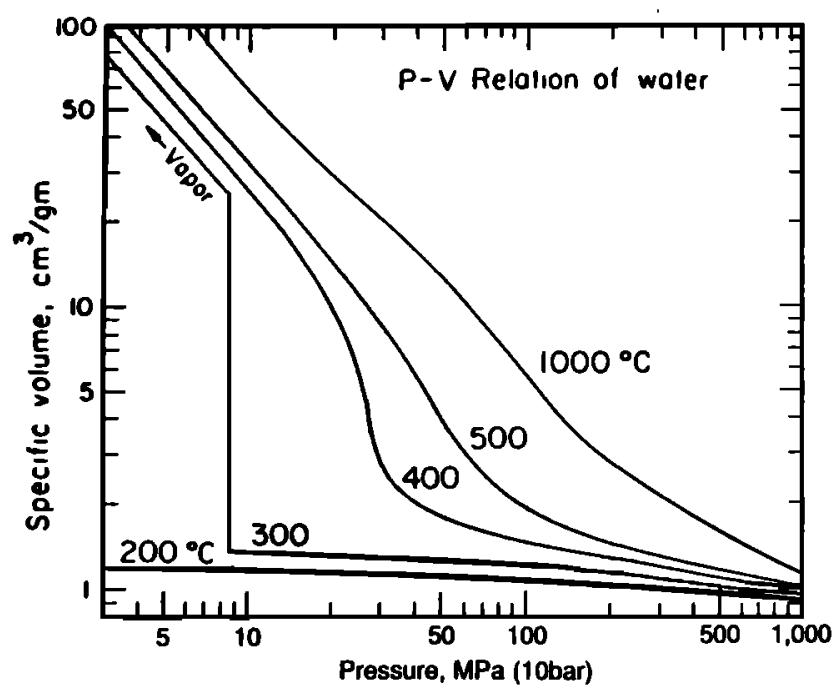

Fig. 9. Equation of state of water [Kennedy and Holser, 1966] (Modified from Anderson and Whitcomb [1973]). 
The volume of magma $\Delta V_{m}$ is roughly given by $\Delta V_{m}$ $=\left(\rho_{H} C_{H} / \rho_{B} C_{B}\right) \Delta V$, where $\rho_{H}$ and $\rho_{B}$ are the density of water and basalt, respectively, $C_{H}$ and $C_{B}$ are the specific heat of water and basalt, respectively, and $\Delta V$ is the injection volume. Since $C_{H} / C_{B}=4$, and $\rho_{H} / \rho_{B}=1 / 30$ to $1 / 90$ for pressures of 500 to 200 bars, $\Delta V_{m}$ is approximately $1 / 10$ of $\Delta V$. Since $\Delta V$ is estimated to be $0.018 \mathrm{~km}^{3}, \Delta V_{m}$ is about $0.0018 \mathrm{~km}^{3}$.

\section{ALTERNATIVE SOURCES}

In view of the indeterminacy of the isotropic component we consider the following alternatives.

\section{Eruption}

The equivalent force system we obtained could be interpreted as an eruption. If an eruption occurred under deep sea (e.g., deeper than $1000 \mathrm{~m}$ ), the confining pressure is so large (larger than 100 bars) that the style of eruption could be very different from that of normal eruptions on land. Because of the large pressure, the eruption would probably look like a horizontal injection. Although no obvious evidence (e.g., change in water color, etc.) for underwater eruptions was observed for this event (A. Kubotera, personal communication, 1985), a deep water eruption could have escaped notice by surface observations.

\section{Isotropic Explosion}

If the source is an embedded explosion, it can be represented by an isotropic source (e.g., $k=2$ ). However, substitution of numerical values of the excitation functions into (3) reveals that $V_{R}$ changes sign from the CLVD case, which is inconsistent with the observation.

\section{Collapse}

A large scale collapse of the seafloor can be represented by a vertical single force. However, for a collapse, the first motion in the far field should be down which contradicts the data and rules out a large-scale collapse.

\section{Multiple Event}

A CLVD source can be decomposed in two double couples. It is therefore possible that two earthquakes occurred almost simultaneously in such a way that Love waves from the two events interfered destructively. However, a total scalar moment of the order of $5 \times 10^{24} \mathrm{dyn} \mathrm{cm}$ is far too small to excite the observed large tsunamis.

\section{CONCLUSION}

The disparity between the tsunami magnitude and earthquake magnitude strongly suggests that the 1984 Tori Shima event is not an ordinary earthquake. Long-period seismic radiation is also anomalous. Love waves are almost absent, and Rayleigh waves are radiated with equal amplitude and phase in all directions. A simple double-couple model cannot explain these observations. With the assumption of no net volume change at the source, these data can be best explained by a compensated linear vector dipole (CLVD).
Centroid moment tensor inversion of long-period body waves and surface waves yields an almost identical solution. This CLVD source can be interpreted as a horizontal fluid injection.

This event is located near the Smith depression (Figure 1) which is one of the nascent back arc basins just behind the Bonin arc. The basins are filled with thick sediments, and numerous young volcanoes are found near this site. In this tectonic environment, magmatic injection is most likely to occur. However, the time scale of the seismic event seems too short for magma injection to occur. A more likely mechanism involves water-magma interaction. The injection may be viewed as hydrofracturing driven by supercritical water heated by injected magma. The estimated volume of injected water is about $0.018 \mathrm{~km}^{3}$ and that of basaltic magma is about $10 \%$ of this. This type of deformation at a shallow depth is more efficient for tsunami generation than faulting with the same scalar moment.

Acknowledgments. We benefitted from discussions with many colleagues when the initial draft was written in 1986, to mention a few: Brad Hager, Don Anderson, Ed Stolper, Akira Kubotera, Katsuyuki Abe, Tokutaro Hatori, Barclay Kamb, Tom Heaton, Emile Okal, and Herbert Shaw. Reviews by Tom Heaton and Greg Beroza were helpful in making the final revision. Collaboration with Kenji Satake on interpretation of tsunamis helped us a great deal in finalizing the model. This work was partially supported by NSF grant EAR 89-15987 and U.S. Geological Survey grant 14-08-0001-G1356. Contribution 5142, Division of Geological and Planetary Sciences, California Institute of Technology.

\section{REFERENCES}

Abe, K., Tsunami and mechanism of great earthquakes, Phys. Earth Planet. Inter., 7, 143-153, 1973.

Abe, K., Size of great earthquakes of 1873-1974 inferred from tsunami data, J. Geophys. Res., 84, 1561-1568, 1979.

Anderson, D. L., and J. H. Whitcomb, Time dependent seismology, $J$. Geophys. Res., 80, 1497-1503, 1975.

Barker, J. S., and H. Kanamori, Analysis of the teleseismic body waves for the June 13, 1984 earhquake near Tori Shima, Japan (abstract), Eos Trans. AGU, 67, 1117, 1986.

Barker, J. S., and C. A. Langston, Moment tensor inversion of complex earthquakes, Geophys. J. R. Astron. Soc., 68, 777-803, 1982.

Delaney, P. T., Rapid intrusion of magma into wet rock: Groundwater flow due to pore pressure increases, J. Geophys. Res., 87, 7739-7756, 1982.

Den, N., Crustal structure in the Westem Pacific Ocean, in The Crust and Upper Mantle of the Japanese Area, part 1, Geophysics, edited by S. Miyamura and S. Uyeda, pp. 57-68, Earhquake Research Institute, University of Tokyo, Tokyo, 1972.

Dziewonski, A. M., J. E. Franzen, and J. H. Woodhouse, Centroid moment tensor solutions for April-June, 1984, Phys. Earth Planet. Inter., 37, 87-96, 1985.

Ekström, G., Evidence for source complexities of the 1980 Mammoth Lakes earthquakes (abstract), Eos Trans. AGU, 64, 7691983.

Ekstròm, G., Avery broadband inversion method for the recovery of earthquake source parameters, Tectonophysics, 166, 73-100, 1989.

Hatori, T., Tsunami magnitude and seismic moment, J. Seismol. Soc. Jpn., 31, 25-34, 1978.

Hatori, T., Irregular tsunami generated by the Torishima-Kinkai earthquake on June 13, 1984 (in Japanese), Bull. Earthquake Res. Inst. Univ. Tokyo, 60, 87-95, 1985.

Heaton, T. H., and R. E. Heaton, Static deformations from point forces and force couples located in welded elastic Poissonian halfspaces: Implications for seismic moment tensors, Bull. Seismol. Soc. Am., 79, 813-841, 1989.

Honza, E., and K. Tamaki, The Bonin Ațc, The Ocean Basins and Margins, vol. 7A, edited by A. E. M. Naim, F. G. Stehli, and S. Uyeda, pp. 459-502, Plenum, New York, 1985.

Ishimoto, M., Existence d'une source quadruple au foyer sismique' apres 
l'etude de la distribution des mouvements initiaux desecousses sismiques, Bull. Earthquake Res. Inst. Univ. Tokyo, 10, 453-471, 1932.

Julian, B. R., Evidence for dike intrusion earhquake mechanisms near Long Valley Caldera, Califomia, Nature, 303, 323-325, 1983.

Julian, B. R., and S. A. Sipkin, Earthquake processes in the Long Valley Caldera area, Califomia, J. Geophys. Res., 90, 11,155-11,169, 1985.

Kanamori, H., and L. Astiz, The 1983 Akita-Oki earthquake $\left(M_{W}=7.8\right)$ and its implications for systematics of subduction earthquakes, Earthquake Predict. Res., 3, 305-317, 1985.

Kanamori, H., and J. W. Given, Use of long-period surface waves for rapid determination of earthquake source parameters, Phys. Earth Plonet. Inter., 27, 8-31, 1981.

Kennedy, G. C., and W. T. Holser, Pressure-volume-temperature and phase relations of water and carbon dioxide, in Handbook of Physical Constants, edited by S. P. Clark, Jr., pp. 371-383, Geological Society of America, Boulder, Colo., 1966.

Morimoto, R., and J. Ossaka,The 1952-1953 submarine enption of the Myojin Reef near the Bayonnaise Rocks, Japan (1), Bull. Earthquake Res. Inst. Univ. Tokyo, 33, 221-250, 1955.

Okada, M.,Tsunamis generated by the June 13, 1984 earthquake near Torishima Island (abstract), Programm. Abstr. Seismol. Soc. Jpn., no. 2, B79, 1984.

Satake, K., and H. Kanamori, Abnormal tsunamis caused by the June 13, 1984, Torishima, Japan, earthquake, J. Geophys. Res., 96, 19,933$19,939,1991$.

Shaw, H. R., The fracture mechanisms of magma transport from the mantle to the surface, in Physics of Magmatic Processes, edited by B. Hargraves, pp. 201-263, Princeton University Press, Princeton, N. J., 1980.

Sipkin, S. A., Estimation of earthquake source parameters by the inversion of waveform data: Synthetic waveforms, Phys. Earth Planet. Inter., 30, 242-259, 1982.

Sipkin, S. A., Interpretation of nondouble-couple earthquake mechanisms derived from moment tensor inversion, J. Geophys. Res., 91, 531-547, 1986.

Spence, D. A., and D. L. Turcotte, Magma-driven propagation of cracks, J. Geophys. Res., 90, 575-580, 1985.

Spudich, P. K. P., M. H. Salisbury, and J. A. Orcutt, Ophiolites found in the oceanic crust?, Geophys. Res. Lett., 5, 341-344, 1978.

Wallace, T. C., A reexamination of the moment tensor solutions of the 1980 Mammoth Lakes earthquakes, J. Geophys. Res., 90, 171-176, 1985.

J. S. Barker, Department of Geological Sciences and Environmental Studies, State University of New York at Binghamton, Binghamton, NY 13901.

A. Dziewonski and G. Edström, Department of Earth and Planetary Sciences, Harvard Universily, Cambridge, MA 02138.

H. Kanamori, Seismological Laboratory, California Institute of Technology, Pasadena, CA 91125.

S. A. Sipkin, U. S. Geological Survey, Branch of Global Seismology and Geomagnetism, Box 25046, MS 967, Denver, CO 80225-0046.

(Received April 29, 1992;

revised November 19, 1992;

accepted December 4, 1992) 